\title{
Occupant Dynamics in Rollover Crashes: Influence of Roof Deformation and Seat Belt Performance on Probable Spinal Column Injury
}

\author{
Martha W. Bidez, ${ }^{1}$ John E. Cochran Jr., ${ }^{2}$ Dottie King, ${ }^{3}$ and Donald S. Burke III ${ }^{4}$ \\ ${ }^{1}$ Department of Biomedical Engineering, University of Alabama at Birmingham, 2100 3rd Avenue North, Suite 410, \\ Birmingham, AL 35203, USA; ${ }^{2}$ Department of Aerospace Engineering, Auburn University, Auburn, AL, USA; ${ }^{3}$ The King \\ Consulting Group, Inc., Birmingham, AL, USA; and ${ }^{4}$ Bidez \& Associates, Birmingham, AL, USA
}

(Received 20 November 2006; accepted 6 July 2007; published online 20 July 2007)

\begin{abstract}
Motor vehicle crashes are the leading cause of death in the United States for people ages 3-33, and rollover crashes have a higher fatality rate than any other crash mode. At the request and under the sponsorship of Ford Motor Company, Autoliv conducted a series of dynamic rollover tests on Ford Explorer sport utility vehicles (SUV) during 1998 and 1999. Data from those tests were made available to the public and were analyzed in this study to investigate the magnitude of and the temporal relationship between roof deformation, lap-shoulder seat belt loads, and restrained anthropometric test dummy (ATD) neck loads.

During each of the three FMVSS 208 dolly rollover tests of Ford Explorer SUVs, the far-side, passenger ATDs exhibited peak neck compression and flexion loads, which indicated a probable spinal column injury in all three tests. In those same tests, the near-side, driver ATD neck loads never predicted a potential injury. In all three tests, objective roof/ pillar deformation occurred prior to the occurrence of peak neck loads $\left(F_{z}, M_{y}\right)$ for far-side, passenger ATDs, and peak neck loads were predictive of probable spinal column injury. The production lap and shoulder seat belts in the SUVs, which restrained both driver and passenger ATDs, consistently allowed ATD head contact with the roof while the roof was contacting the ground during this $1000 \mathrm{~ms}$ test series. Local peak neck forces and moments were noted each time the far-side, passenger ATD head contacted ("dived into") the roof while the roof was in contact with the ground; however, the magnitude of these local peaks was only $2-13 \%$ of peak neck loads in all three tests. "Diving-type" neck loads were not predictive of injury for either driver or passenger ATD in any of the three tests.
\end{abstract}

Keywords-SUV, Roof crush, Spinal injury, Restraint system, Crash test.

Address correspondence to Martha W. Bidez, Department of Biomedical Engineering, University of Alabama at Birmingham, 2100 3rd Avenue North, Suite 410, Birmingham, AL 35203, USA. Electronic mail: mbidez@uab.edu

\section{INTRODUCTION}

Motor vehicle crashes are the leading cause of death in the United States for persons of every age from 3 through $33 .{ }^{18}$ Rollover crashes, in particular, have a higher fatality rate than any other crash mode. Of the $6,159,287$ police reported crashes in 2005 in the United States, only $4.1 \%$ involved a rollover. Yet, rollovers accounted for $34.4 \%(10,816)$ of all passenger vehicle fatalities. The fatality rate (defined as deaths per 100,000 registered vehicles) in rollover crashes is more than two and one-half times higher in sport utility vehicles (SUVs) than in passenger cars ( 8.28 vs. 3.22 , respectively). Another 149,406 individuals sustained serious injuries in rollover crashes in 2005, approximately $30 \%$ of whom were occupants of SUVs. ${ }^{18}$

Measurement tools are required to evaluate appropriate intervention strategies to reduce the mortality and morbidity associated with rollover crashes. The Abbreviated Injury Scale (AIS) and Harm value (HARM) are two such measures, which are used to compare injuries of different types and severities. ${ }^{9}$ The AIS reflects "threat to life" (or risk of death) and stratifies injuries into six categories (AIS 1-6) with AIS 6 defined as an "untreatable" injury. The maximum AIS (MAIS) score refers to the most severe injury sustained in a specific individual. The highest rate of seriously injured (MAIS 3+) children 4-12 years old occurs in rollovers, more than double any other crash mode. ${ }^{22}$ One study reported that despite the increased weight of SUVs, the risk of injury for children in SUVs was similar to that for passenger cars, which may be due to the increased tendency of SUVs to roll over. ${ }^{6}$ HARM is a mathematical measure that applies a weighting factor to each injured, yet surviving occupant, which includes both monetary costs of the injury (i.e., direct costs associated with the loss of wages) and comprehensive costs (i.e., monetary costs plus nonmonetary costs). ${ }^{9,14}$ Importantly, the non-monetary 
costs include such measures as loss of functional capacity and quality of life. In rollover crashes, the highest HARM is reflected in the population of occupants who survive the crash, yet sustain catastrophic injury, including permanent brain and/or spinal cord injury. ${ }^{9}$

A major source of HARM in rollover crashes results from occupant contact with the vehicle roof, support pillars and side headers. ${ }^{9}$ According to Digges et al. "Countermeasures to reduce rollover casualties include increased belt use, and technological interventions to prevent ejection and reduce the severity of body contacts with the vehicle interior." 9 Hugh DeHaven outlined principles for designing vehicles for human transport in 1952, and stated that "the package (the passenger compartment) should not collapse under expected conditions of force, thereby exposing objects (and people) inside it to damage." " Closely related to this principle, DeHaven stated that "the packaging structures which shield the inner container must not be made of brittle or frail materials; they should resist force by yielding and absorbing energy applied to the outer container so as to cushion and distribute impact forces and thereby protect the inner container."

Franchini ${ }^{11}$ reported the importance of maintaining the integrity of the occupant compartment (referred to as "survival space") for belted occupants during a crash event. Few studies, however, have experimentally evaluated the influence of dynamic roof deformation with concomitant loss of occupant survival space as a potentially preventable cause of head and cervical spine injuries in rollover crashes. Bahling et al. ${ }^{1}$ conducted rollover and drop tests of late 1980s model Chevrolet Malibu passenger cars using lap-shoulder belted anthropomorphic test dummies (ATDs) to evaluate the influence of roof strength on injury mechanics. In several studies, Moffatt and other investigators reported on a customized, dynamic test procedure with controlled roof impacts of passenger vans and sedans. ${ }^{3,5,15}$ Both groups concluded that "potentially injurious impacts" (defined by these authors as $2000 \mathrm{~N}$ recorded by the ATD upper neck sensor) occurred prior to significant roof crush and that enhanced roof strength made no difference in the likelihood of serious neck injury to restrained occupants. These conclusions have been contradicted in other literature, albeit without the benefit of scientific data from comparable full-scale, dynamic rollover crash tests. ${ }^{12,13}$

Recently, the raw data from a series of full-scale, dynamic rollover tests of 1998-1999 model year Ford Explorer SUVs, using fully instrumented ATDs, were made publicly available to the scientific community. ${ }^{2}$ These tests were conducted using a standardized test methodology specified by Federal Motor Vehicle
Safety Standard (FMVSS) 208 of the U.S. Department of Transportation (FMVSS 20849 CFR Ch. V (10-0104 Edition)). These data provide the first opportunity to analyze the dynamics of belted occupants within a contemporary SUV in a standardized rollover test environment.

The authors used the described data in the present study. The study's objective was to investigate both the magnitude of and the temporal relationship between dynamic roof deformation, lap-shoulder seat belt loads, and restrained ATD neck loads in these FMVSS 208 dolly rollover tests of Ford Explorer SUVs.

\section{MATERIALS AND METHODS}

Three full-scale dolly rollover tests of 1998-1999 Explorer SUVs were sponsored by Ford Motor Company and conducted at the North American Autoliv test facility ${ }^{1}$ according to the standardized FMVSS 208 test protocol. This standard, issued by the National Highway Transportation Safety Administration (NHTSA) in 1971, outlines vehicle crash performance requirements designed for improving occupant protection. Described within FMVSS 208 is a voluntary, dolly rollover test used to evaluate occupant protection during a lateral rollover. This standardized test procedure was used for all three SUV rollover tests.

The FMVSS 208 test procedure involves accelerating a rollover dolly carrying a test vehicle to a set velocity and then rapidly decelerating the dolly, causing the vehicle to release, trip, and enter a lateral roll. The SUVs were first placed on a dolly fixed with a rigid, angled platform positioned 9 in. from the ground and $23^{\circ}$ from the horizontal. To assure that the roll was driver-side leading (i.e., that the driver's side contacted the ground first), each vehicle was situated on the platform so that its driver's side tires rested along a $4 \mathrm{in}$. lip at the forward edge of the test platform, as shown in Figs. 1a and $1 \mathrm{~b}$.

The vehicle and dolly were then accelerated along a straight path perpendicular to the longitudinal axis of the vehicle. The dolly was then decelerated rapidly (minimum deceleration rate of $20 \mathrm{~g}$ for $0.04 \mathrm{~s}$ ), resulting in vehicle trip and subsequent rollover. The target speed for all Explorer tests was $30 \mathrm{mph}$. The vehicle identification number (VIN) and actual dolly launch velocity for each of the three tests are summarized in Table 1.

\footnotetext{
${ }^{1}$ North American Headquarters and North American Technical Center; 1320 Pacific Drive, Auburn Hills, MI 48326-1569.
} 


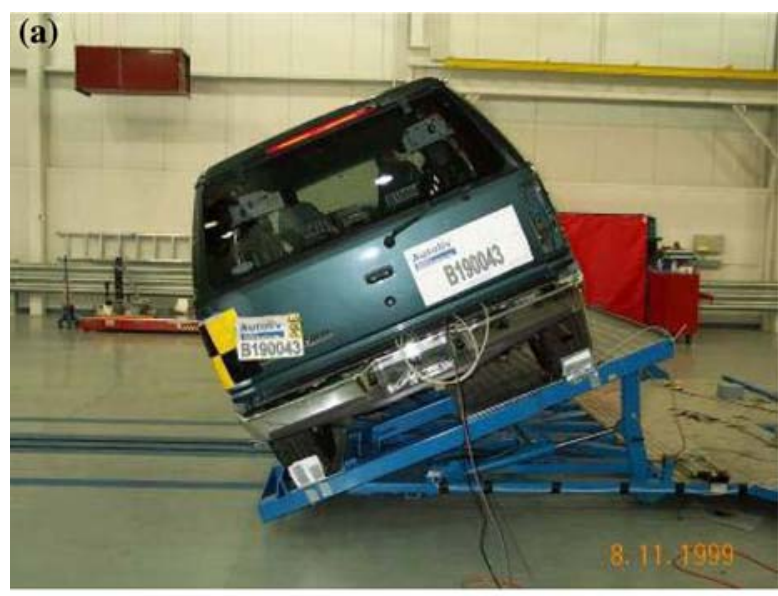

(b)

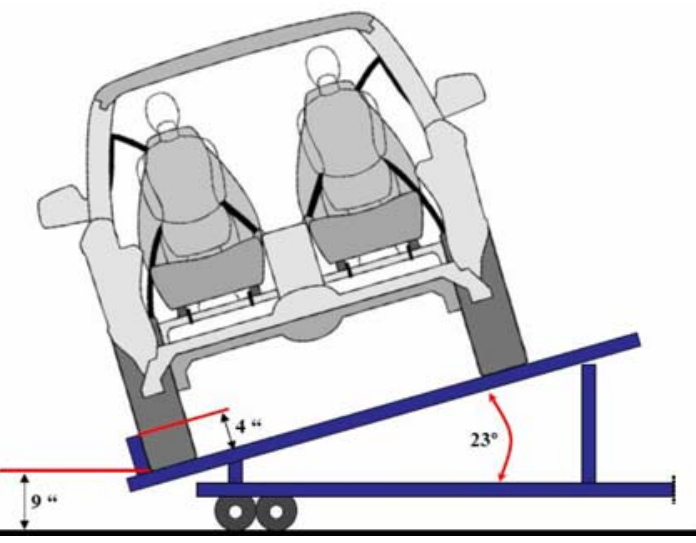

FIGURE 1. (a) FMVSS 208 dynamic rollover pre-test setup of SUV test B190043 on a dolly rollover cart; (b) critical dimensions of FMVSS 208 dolly.
Vehicle and ATD Instrumentation

Triaxial and biaxial accelerometers were installed in each SUV to measure vehicle structural dynamics during the rollover tests. Accelerations were recorded at each of the following vehicle structure locations in coordinate systems consistent with SAE J211 guidelines (SAE J211-1 REV DEC03), as shown in Figs. 2a and $2 \mathrm{~b}$, and Table 1 .

- Center of Gravity (CG) $(x, y, z)$

- Left (driver) roof rail at

- A-pillar $(y, z)$

- B-pillar $(y, z)$

- C-pillar $(y, z)$

- Right (passenger) roof rail at

- A-pillar $(y, z)$

- B-pillar $(y, z)$

- C-pillar $(y, z)$

In each test, two Hybrid III 50th percentile male, instrumented ATDs were placed in the front seats of Ford Explorer SUVs and restrained with lap-shoulder belts that were affixed with load cells. Time synchronized with all other sensors and cameras in the experimental setup, these load cells continuously recorded tensile forces in the webbing of the lap and

TABLE 1. Test conditions.

\begin{tabular}{|c|c|c|c|c|c|c|c|c|}
\hline \multirow[b]{2}{*}{ Autoliv test number } & \multirow[b]{2}{*}{ Test description } & \multirow{2}{*}{$\begin{array}{l}\text { Data } \\
\text { sampling } \\
\text { rate }\end{array}$} & \multirow{2}{*}{$\begin{array}{l}\text { Sampling } \\
\text { duration }\end{array}$} & \multirow[b]{2}{*}{ Test date } & \multirow[b]{2}{*}{ Accelerometer } & \multicolumn{3}{|c|}{ Coordinates (mm) } \\
\hline & & & & & & $x$ & $Y$ & $Z$ \\
\hline \multirow[t]{7}{*}{ B190042 } & FMVSS 208 Rollover & $20,000 \mathrm{~Hz}$ & $\sim 13,000 \mathrm{~ms}$ & $8 / 10 / 99$ & Center of gravity & 2073.10 & -24.50 & 975.00 \\
\hline & (VIN1FMCU24E5VUC19292) & & & & Driver's rail at A-pillar & 2038.20 & -596.10 & 1770.0 \\
\hline & $\left(23^{\circ} ; 30.5 \mathrm{mph}\right)$ & & & & Driver's rail at B-pillar & 2776.40 & -571.30 & 1863.30 \\
\hline & & & & & Driver's rail at C-pillar & 3209.70 & -580.60 & 1871.40 \\
\hline & & & & & Passenger's rail at A-pillar & 2011.80 & 592.10 & 1758.60 \\
\hline & & & & & Passenger's rail at B-pillar & 2786.60 & 532.60 & 1857.10 \\
\hline & & & & & Passenger's rail at C-pillar & 3234.40 & 523.30 & 1868.20 \\
\hline \multirow[t]{7}{*}{ B190043 } & FMVSS 208 Rollover & $20,000 \mathrm{~Hz}$ & $\sim 13,000 \mathrm{~ms}$ & $8 / 11 / 99$ & Center of gravity & 2231.0 & -4.1 & 761.3 \\
\hline & (VIN1FMDU34E6VUB99290) & & & & Driver's rail at A-pillar & 2077.2 & -543.7 & 1626.8 \\
\hline & (23; $30.4 \mathrm{mph})$ & & & & Driver's rail at B-pillar & 2637.2 & -535.0 & 1644.0 \\
\hline & & & & & Driver's rail at C-pillar & 3436.0 & 572.4 & 1598.0 \\
\hline & & & & & Passenger's rail at A-pillar & 2077.9 & 573.5 & 1564.7 \\
\hline & & & & & Passenger's rail at B-pillar & 2636.5 & 569.7 & 1625.5 \\
\hline & & & & & Passenger's rail at C-pillar & 3436.3 & -543.0 & 1617.6 \\
\hline \multirow[t]{7}{*}{ B180220 } & FMVSS 208 Rollover & $12,500 \mathrm{~Hz}$ & $\sim 8000 \mathrm{~ms}$ & $12 / 10 / 98$ & Center of gravity & 2231.0 & -4.1 & 761.3 \\
\hline & (VIN1FMDU35P5VUC14510) & & & & Driver's rail at A-pillar & 2077.2 & -543.7 & 1626.8 \\
\hline & $\left(23^{\circ} ; 30.9 \mathrm{mph}\right)$ & & & & Driver's rail at B-pillar & 2637.2 & -535.0 & 1644.0 \\
\hline & & & & & Driver's rail at C-pillar & 3436.0 & 572.4 & 1598.0 \\
\hline & & & & & Passenger's rail at A-pillar & 2077.9 & 573.5 & 1564.7 \\
\hline & & & & & Passenger's rail at B-pillar & 2636.5 & 569.7 & 1625.5 \\
\hline & & & & & Passenger's rail at C-pillar & 3436.3 & -543.0 & 1617.6 \\
\hline
\end{tabular}



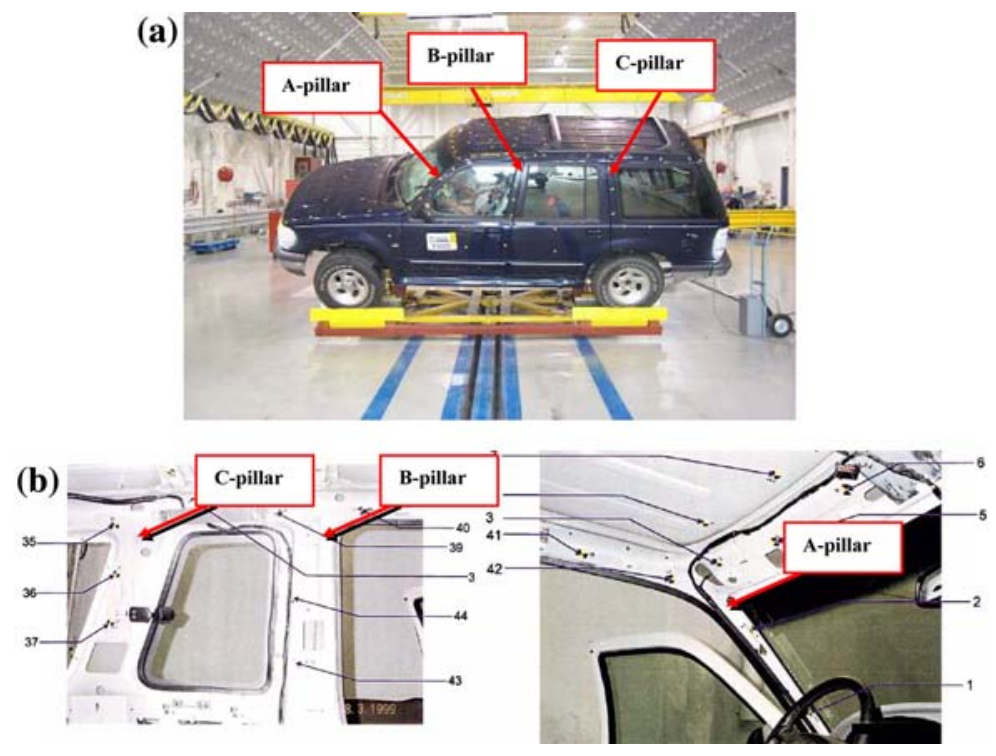

FIGURE 2. (a) Exterior view of test vehicle indicating A, B, and C-pillars; (b) interior view of test vehicle-accelerometers were mounted at the roof rail-to-pillar junction at the A, B, and C-pillars for both driver and passenger sides of the Ford Explorer SUVs.

shoulder belts. Both ATDs were positioned in their respective seats according to reference FMVSS 208 Dummy Positioning Procedure with the seats located in the mid-track position. Given that the vehicle was positioned to roll driver-side leading, the driver ATD represented the "near-side" occupant and the passenger ATD, the "far-side" occupant in this test series. The following sensor outputs were recorded continuously throughout each rollover test for both driver and passenger ATDs:

- Head CG acceleration $(x, y, z)$

- Upper Neck

- Force $(x, y, z)$

- Moment (x, y, z)

- Lower Neck

- Force $(x, y, z)$

- Moment $(x, y, z)$

- Chest

- Acceleration $(x, y, z)$

- Deflection

- Pelvis Acceleration $(x, y, z)$

- Femur Force $\left(F_{z}\right.$, right and left)

Dynamic motion of the SUVs was visually recorded by up to 10 high speed external cameras, which were time synchronized with the cart release trigger and

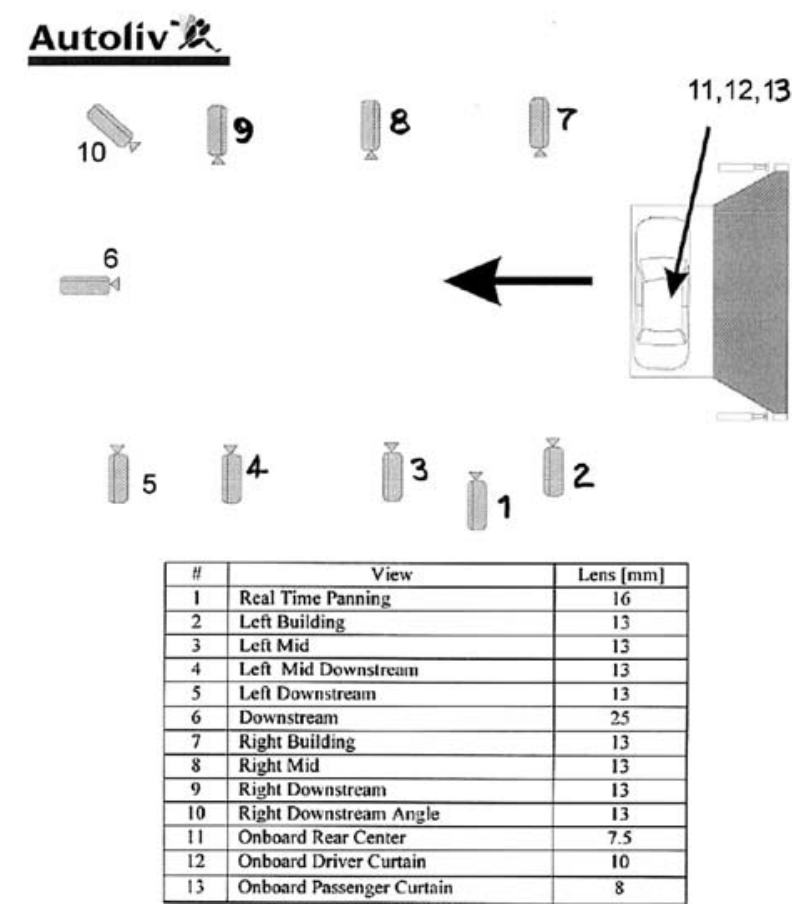

FIGURE 3. External camera setup.

imaged at 500 frames/s. (Fig. 3) Clocks that were positioned along the test track were visible in the external camera views throughout the roll sequence. Targets were affixed to the rear aspect of the driver and passenger ATD heads and were visible by the same camera monitoring the onboard time clock. Up to three onboard, high speed cameras recorded ATD kinematics as a function of time using the onboard 
clock, which was also time synchronized with the cart release trigger, external cameras, and electronic sensors affixed to both ATDs, the seat belts, and the SUV structure.

With the cart positioned according to FMVSS 208 specifications, the data acquisition system was set up and armed for trigger. Time zero for all data acquisition was provided by a contact switch at both shock absorbers to indicate the start of cart deceleration. The data-sampling rates for each test are provided in Table 1 .

\section{Data Analysis}

The raw ASCII sensor data retrieved from the ATD and vehicle-mounted transducers were filtered according to the SAE J211 channel filtering class (CFC) requirements to remove the effects of crash related noise on the sensor readings. Each CFC specifies that the channel frequency response lies within limits detailed in SAE J211. Neck forces, neck moments, and vehicle data were filtered at CFC 1000, CFC 600, and CFC 60 accordingly. Subsequently, the filtered vehicle acceleration data were transformed into a vehiclefixed, center-of-gravity, coordinate system using MATLAB $^{\circledR}$ (registered trademark of The Mathworks, Inc.). Roof rail accelerations were transformed by subtracting the center of gravity accelerations from each measurement as a function of time. The result of the transformations was the acceleration of the roof rail relative to the vehicle's center of gravity. The transformed roof rail acceleration values provided insight into when and in what direction the rail was moving. Transformed data was then compared to the ATD neck and seat belt loads as a function of time. The accelerations recorded by the rail sensors were influenced by both vehicle rotation (angular velocity) and localized pillar deformation. The contribution due to vehicle rotation was made at a low frequency given that the peak roll rate of the vehicle at any time during the test interval $(0-1000 \mathrm{~ms})$ was approximately 350 $400^{\circ}$ s (i.e., less than $2 \mathrm{~Hz}$ ). Thus, all higher frequency accelerations were necessarily due to localized structural deformation.

The sensor outputs from the driver and passenger roof rail accelerometers positioned at the B-pillar were used as a quantitative definition of roof intrusion (i.e., "objective roof crush") into the occupant survival space. The mathematically transformed driver and passenger roof rail acceleration tracings in the present study provided objective evidence of the time interval(s) when roof/pillar deformation occurred, and the time of deformation was corroborated through careful scrutiny of the high speed video images ("observable" roof crush). Objective roof crush in our study was defined under the following necessary, contemporaneous conditions:

(1) Vertical and/or lateral rail acceleration peak(s) "downward" and/or inboard toward the restrained ATD

(2) External camera video images consistent with SUV roof-to-ground contact

(3) Onboard camera video images consistent with a compromise in occupant survival space (i.e., reduced headroom)

Roof rail accelerations, seat belt loads and peak ATD axial neck force $\left(F_{z}\right.$, axial compression/tension) and moments $\left(M_{y}\right.$, chin-to-chest flexion, and $M_{x}$, earto-shoulder lateral bending) were compared to the high-speed video data to validate the correlation in time between the presence of objective roof crush and the development of peak ATD neck and seat belt loads.

\section{RESULTS}

Results are presented and discussed for the first full second of the roll sequence for each of the three SUV tests, which includes the initial driver-side-to-ground contact and full roof contact, followed by the first passenger-side-to-ground contact.

In all three tests, the external high-speed cameras recorded continuous roof-to-ground contact from the first contact of the driver's roof rail with the ground until the end of the $1000 \mathrm{~ms}$ period, which corresponded to approximately $5 / 8$ roll. Onboard high speed video cameras recorded the front passenger compartment of each SUV, capturing the kinematics of the ATDs as well as the deformation of the roof header and side roof rails during the rollover event. These cameras recorded inboard displacement of roof rails ("observable" roof crush) of both driver and passenger-side roof rails during the respective roof railto-ground contact for all three tests. The onboard clock, which was recorded by the interior cameras, allowed for a time-synchronized comparison of this data to the sensor output of the ATD neck transducers and roof rail accelerometers.

In all three tests, the head of each lap-shoulder belt restrained ATD (driver and passenger) contacted the roof two or more times during the first $1000 \mathrm{~ms}$ roll interval as indicated by increased neck compression loads (negative $F_{z}$ values) recorded by the ATDs' upper neck sensor (Fig. 4). The time of occurrence of each peak neck load for the driver and passenger ATD head-to-roof contacts (the "Local Maximum" as well as the "Absolute Maximum" or "Peak" neck loads) was consistent with the onboard high speed video data. 


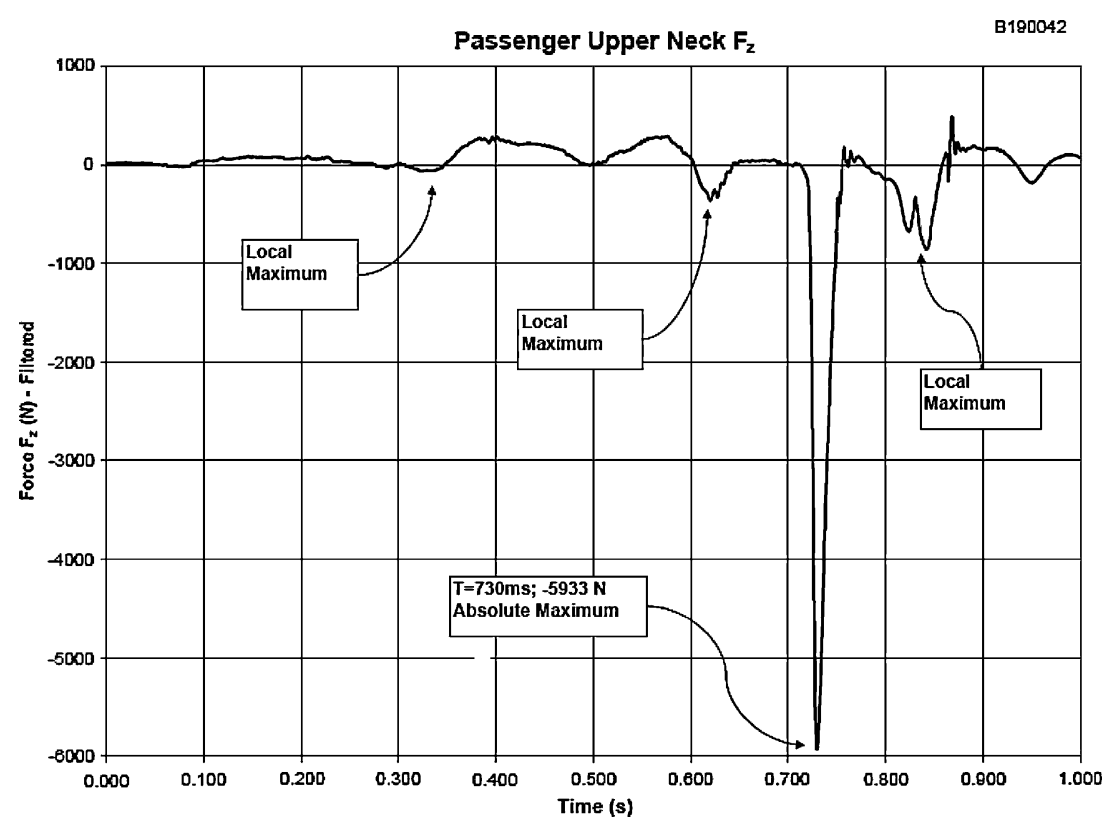

FIGURE 4. Passenger upper neck $F_{z}$ vs. time (Test B190042).

TABLE 2. Magnitudes of Local and Absolute maximum (Peak) neck loads (during time interval of continuous roof-to-ground contact).

\begin{tabular}{|c|c|c|c|c|c|c|}
\hline \multirow[b]{2}{*}{ Test parameter } & \multicolumn{3}{|c|}{ Driver } & \multicolumn{3}{|c|}{ Passenger } \\
\hline & B190042 & B190043 & B180220 & B190042 & B190043 & B180220 \\
\hline $\operatorname{Max}$ peak $F_{z}(\mathrm{~N})^{\mathrm{a}}$ & -958 & -1962 & -1920 & -5933 & -3245 & None $^{\mathrm{b}}$ \\
\hline Local peak (s), $F_{z}$ & -200 & -295 & -223 & -361 & -50 & 200-260 \\
\hline Max peak $M_{y}(\mathrm{~N} \mathrm{~m})$ & 58 & 110 & 94 & 304 & 178 & 261 \\
\hline Local peak (s), $M_{y}$ & 2 & 11 & $2-54$ & $12-22$ & $20-24$ & 10 \\
\hline Max peak $M_{x}(\mathrm{~N} \mathrm{~m})$ & -106 & -124 & -167 & 68 & 98 & 41 \\
\hline Local peak (s), $M_{x}$ & -11 to -18 & $\mathrm{n} / \mathrm{a}$ & -20 to -46 & 9 & 12 & $19-21$ \\
\hline
\end{tabular}

${ }^{\mathrm{a}} F_{z}$ was measured at the dummy upper neck load cell; $M_{y}$ and $M_{x}$ measured at the lower load cell.

${ }^{\mathrm{b}}$ In Test 180220, no absolute maximum $F_{z}$ was identified as all peak neck compression loads were within the range of 200-260 $\mathrm{N}$.

For each of the three tests, the time recorded by the onboard camera during observable ATD head-to-roof contact was within $3 \mathrm{~ms}$ of the time recorded by the neck sensors for peak neck loads. Peak axial neck force data $\left(F_{z}\right)$ were measured by the ATDs' upper neck sensors and the moment loads $\left(M_{y}\right.$ and $\left.M_{x}\right)$ were measured by the ATDs' lower neck sensors (Table 2).

The near-side (i.e., the driver) ATD recorded Peak axial neck compression $\left(F_{z}\right)$ loads of $-2000 \mathrm{~N}$ or less for all three tests. Peak neck flexion $\left(M_{y}\right)$ loads for the driver ATD resulted in chin-toward-chest head motion and were within a range of $58-110 \mathrm{~N} \mathrm{~m}$ for all three tests. In contrast, the far-side (i.e., the passenger) ATD recorded Peak neck $F_{z}$ values in the range of -3244 to $-5933 \mathrm{~N}$ for two out of three tests. In Test B180220, no Absolute Maximum $F_{z}$ value was identified as all Local Maxima compression loads were within the range of -200 to $-260 \mathrm{~N}$. The Peak neck flexion $\left(M_{y}\right)$ loads, recorded by the passenger ATDs, resulted in chin-toward-chest head motion and ranged from 178 to $304 \mathrm{~N} \mathrm{~m}$ for all three tests. The Peak lateral neck bending ear-to-shoulder $\left(M_{x}\right)$ loads ranged from 41 to $98 \mathrm{~N} \mathrm{~m}$ for the passenger ATD, and the driver experienced $M_{x}$ load magnitudes in the range of -106 to $-167 \mathrm{~N} \mathrm{~m}$, for all three tests.

The time of occurrence of objective vertical and lateral roof crush was identified by the roof rail acceleration peak, for both the passenger and driver side roof rails in all three tests (Table 3). Objective roof crush occurred prior to the Absolute Maximum dummy neck loads $\left(F_{z}, M_{y}, M_{x}\right)$ in each of the three tests for both driver and passenger ATDs (Table 3, Fig. 5). The far-side, passenger ATD recorded Peak neck loads within $10 \mathrm{~ms}$ following the time of occurrence of objective roof crush for all three tests. Peak neck loads for the near-side, driver ATD occurred up to $65 \mathrm{~ms}$ 
TABLE 3. Time of occurrence $(\mathrm{ms})$ of roof/pillar deformation and absolute maximum neck loads.

\begin{tabular}{lccccccc}
\hline & \multicolumn{3}{c}{ Driver } & & \multicolumn{2}{c}{ Passenger } \\
\cline { 2 - 3 } Test parameter & B190042 & B190043 & B180220 & & B190042 & B190043 & B180220 \\
\hline Objective roof/pillar deformation (vertical acceleration peaks) & 497 & 513 & 510 & & 730 & $\sim 600-800^{\mathrm{a}}$ & 742 \\
Objective roof/pillar deformation (lateral acceleration peaks) & 497 & 513 & 494 & & 496 & 512 & 495 \\
Peak $F_{z}^{c}$ & 533 & 540 & 516 & 730 & 764 & $\mathrm{n} / \mathrm{a}^{\mathrm{b}}$ \\
Peak $M_{y}$ & 533 & 541 & 517 & 729 & 764 & 751 \\
Peak $M_{x}$ & 537 & 548 & 540 & & 783 & 774 & 760 \\
\hline
\end{tabular}

${ }^{\mathrm{a}} \mathrm{No}$ isolated spike in acceleration was noted; however, a sustained level of roof deformation is reflected in the roof rail tracings and the video footage for this test.

${ }^{\mathrm{b}} \mathrm{No}$ isolated absolute maximum $F_{z}$ value was noted, which differed significantly from the other "local" maximums. This was consistent with the very high peak $M_{y}$ in this test, however, which was noted at $751 \mathrm{~ms}$ (see Table 2).

${ }^{\mathrm{c}} F_{z}$ was measured at the upper neck load cell, whereas $M_{y}$ and $M_{x}$ were measured at the lower neck load cells.

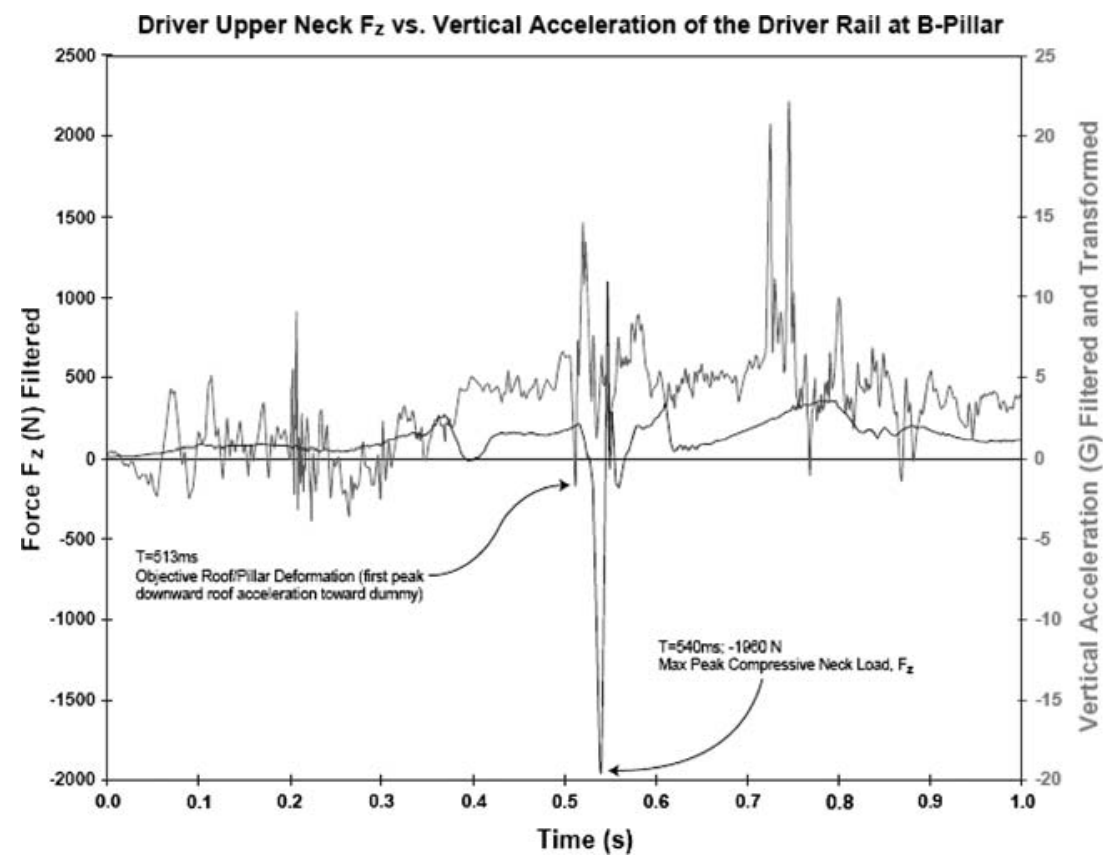

FIGURE 5. Driver upper neck $F_{z}$ vs. vertical acceleration of the driver rail at B-pillar (Test B190043).

following the time of occurrence of objective roof crush for all three tests.

Lap and shoulder belt loads were recorded for both driver and passenger ATDs in all three tests, with the exception of the driver's shoulder belt for test B190043 and passenger shoulder belt for test B180220, both of which experienced sensor failures (Table 4). The Peak lap belt loads for the near-side, driver ATD occurred within $1 \mathrm{~ms}$ of the time of Peak $F_{z}$ and $M_{y}$ neck loads for two out of three tests (Figs. 6,7). In the remaining test (B190042), the Peak lap belt load occurred $22 \mathrm{~ms}$ prior to the time that peak neck $F_{z}$ and $M_{y}$ neck loads occurred in the driver ATD. In contrast, the far-side, passenger ATDs' Peak lap belt loads occurred 65131 ms prior to the time of Peak neck compression $\left(F_{z}\right)$ for two out of three tests and $65-145 \mathrm{~ms}$ prior to the time of Peak neck flexion $\left(M_{y}\right)$ for all three tests (Fig. 8). In Test B180220, the passenger's Peak lap belt load occurred $6 \mathrm{~ms}$ after the time of Peak neck compression, yet $145 \mathrm{~ms}$ before the Peak neck flexion load $\left(M_{y}\right)$.

The driver ATDs' Peak lap belt loads ranged from 548 to $940 \mathrm{~N}$ for the three tests, and the shoulder belt loads were $395-410 \mathrm{~N}$ for two tests (the driver's shoulder belt sensor failed on Test B190043) (Table 4). The passenger ATDs' Peak lap belt loads were similar to those of the driver ATDs', ranging from 705 to $797 \mathrm{~N}$ for all three tests; the shoulder belt loads were 899-953 $\mathrm{N}$ for two of three tests (the passenger's shoulder belt sensor failed on test B180220). 
TABLE 4. Peak belt loads compared to belt loads at time of absolute maximum (peak) neck loads.

\begin{tabular}{|c|c|c|c|c|c|c|}
\hline \multirow[b]{2}{*}{ Test parameter } & \multicolumn{3}{|c|}{ Driver } & \multicolumn{3}{|c|}{ Passenger } \\
\hline & B190042 & B190043 & B180220 & B190042 & B190043 & B180220 \\
\hline Peak lap belt $(\mathrm{N})$ & 548 (511 ms) & 795 (540 ms) & 940 (515 ms) & 797 (599 ms) & 705 (699 ms) & 779 (606 ms) \\
\hline $\begin{array}{l}\text { Peak shoulder belt }(\mathrm{N}) \\
\text { Peak } F_{z}\end{array}$ & 395 (379 ms) & $N / A^{a}$ & 410 (373 ms) & 899 (587 ms) & 953 (689 ms) & $N / A^{a}$ \\
\hline Lap belt $(N)$ & 398 (533 ms) & 789 (540 ms) & 937 (516 ms) & 359 (730 ms) & 115 (764 ms) & 771 (600 ms) \\
\hline $\begin{array}{l}\text { Shoulder belt }(\mathrm{N}) \\
\text { Peak } M_{y}(\mathrm{~N} \mathrm{~m})\end{array}$ & 231 (533 ms) & $N / A^{a}$ & 236 (516 ms) & 337 (730 ms) & 426 (764 ms) & $N / A^{a}$ \\
\hline Lap belt $(\mathrm{N})$ & 393 (533 ms) & 785 (541 ms) & 937 (517 ms) & 361 (729 ms) & 115 (765 ms) & 218 (751 ms) \\
\hline Shoulder belt $(\mathrm{N})$ & 227 (533 ms) & $N / A^{a}$ & 236 (517 ms) & 341 (729 ms) & 417 (764 ms) & $N / A^{a}$ \\
\hline
\end{tabular}

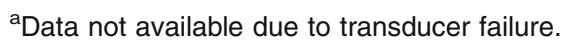

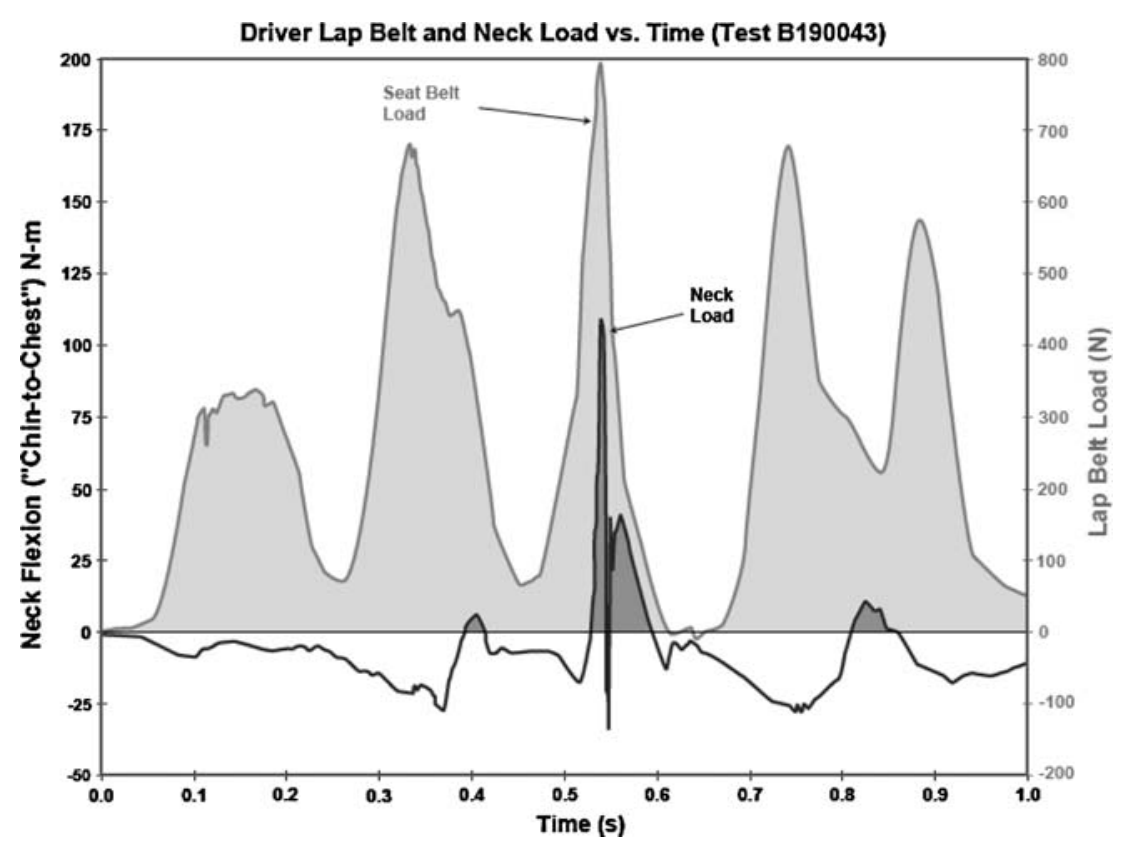

FIGURE 6. Driver lap belt and neck load vs. time (Test B190043).

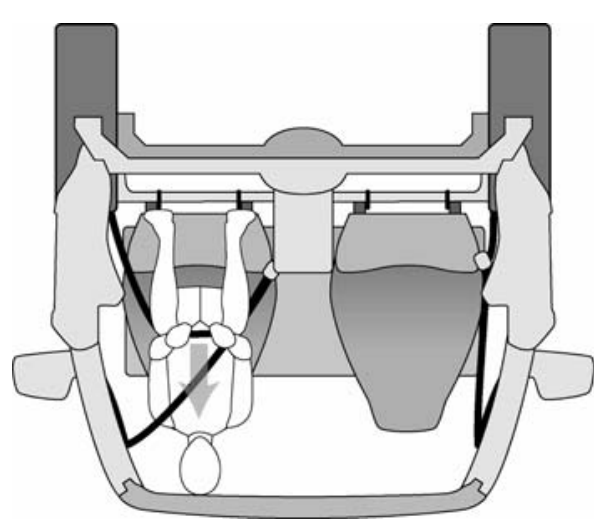

FIGURE 7. Inverted 50th percentile Hybrid III Driver ATD "diving" into roof with lap and shoulder belt providing restraining forces, which reduces neck load.
The near-side, driver ATD lap belt loads at the time of occurrence of the Peak $F_{z}$ and $M_{y}$ neck loads were $72-99 \%$ of the ATDs' respective Peak lap belt load for all three tests (Table 4). In contrast, the far-side, passenger ATD lap belt loads at the time of occurrence of the Peak neck compression $\left(F_{z}\right)$ were less than $45 \%$ of the passenger ATDs' respective Peak lap belt load recorded for two of the three tests. At the time of Peak neck flexion $\left(M_{y}\right)$, the lap belt loads were less than $45 \%$ of the Peak lap belt load for all three tests. Shoulder belt loads for both driver and passenger ATDs at the time of occurrence of the Peak neck $F_{z}$ and $M_{y}$ were $37-58 \%$ of the ATDs' respective Peak shoulder belt loads for two of three tests (load cells malfunctioned in the driver's shoulder belt in test B190043 and passenger's shoulder belt in test B180220). 

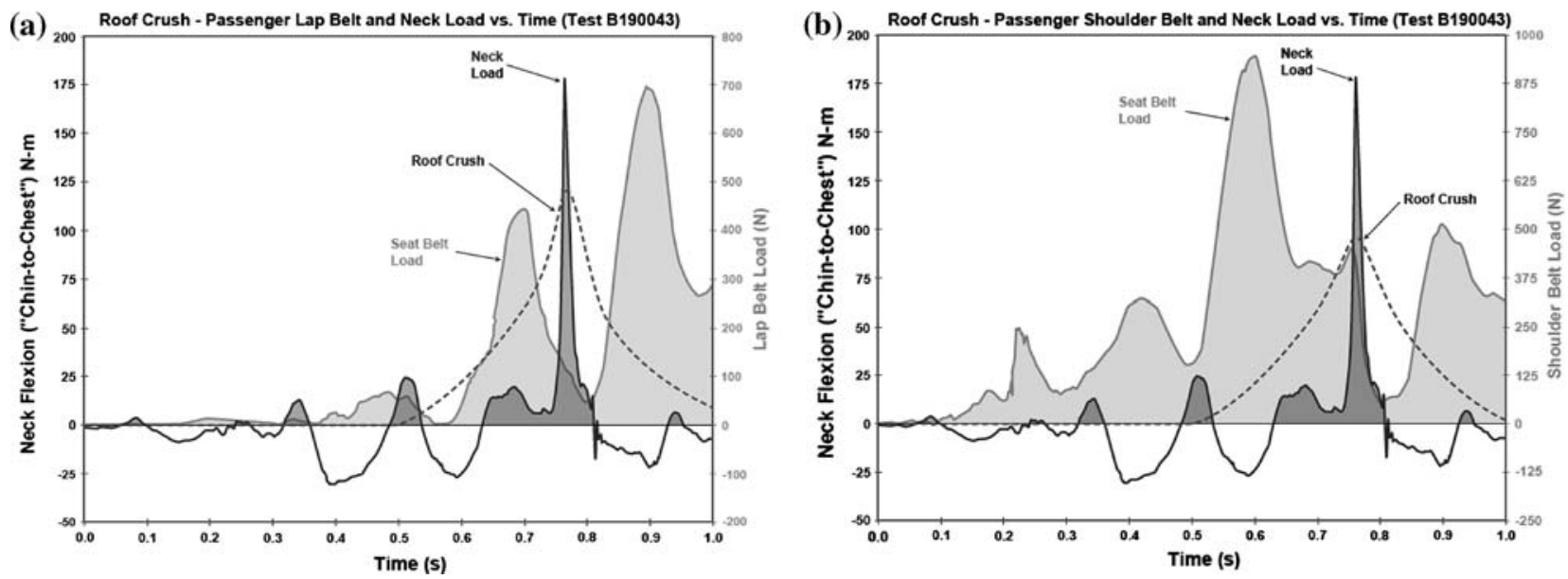

FIGURE 8. (a) Roof crush—passenger lap belt and neck load vs. time (Test B190043); (b) Roof crush—passenger shoulder belt and neck load vs. time (Test B190043).

\section{DISCUSSION}

The three rollover tests of 1998-1999 Ford Explorer SUVs analyzed in the present study represent a unique dataset evaluating occupant dynamics in rollover crashes as represented by Hybrid III ATDs. To the authors' knowledge, this study represents the first published test series of full-scale rollover crashes of a contemporary SUV with time synchronized sensor output from ATD neck transducers, roof rail accelerometers, an onboard high speed clock, and high speed external and internal video cameras.

\section{ATD Biofidelity}

The biofidelity of the Hybrid III ATD in rollover crash conditions is a significant limitation of this study as well as other published rollover studies ${ }^{1,15}$; however, ATD sensor data may be carefully evaluated within such limitations to yield objective insights. The ATDs used in this study were originally designed as a measurement tool in frontal crash tests, not rollovers. Thus, the Hybrid III ATD neck was designed and tested primarily to simulate dynamic head motion in the sagittal plane (neck flexion and extension) ${ }^{8,10}$ The Hybrid III ATD neck was not specifically designed to produce a biofidelic response under axial compression loading, typical of the neck loads resulting from the head-to-roof contacts observed in this study. Researchers have shown that with an axially directed impact to the crown of the ATD head, the ATD lower neck sensor records essentially the same magnitude axial force as the upper neck load cell, whereas the human cadaver neck lower load cell records a much reduced load magnitude compared to the upper load cell. ${ }^{24,29}$ Also, the Hybrid III ATD necks are neither frangible nor viscoelastic; therefore, they cannot accurately simulate individual vertebral displacement and/or fracture.

Notwithstanding the biomechanical differences between the necks of human cadavers and ATD mechanical necks, the $F_{z}$ measurements of the upper load cell of a restrained Hybrid III dummy may provide a reasonable estimate of the initial input load to a restrained occupant's head when it contacts the roof in a rollover crash under similar dynamic conditions (e.g., impact velocity, impact duration). Given that the mass of a Hybrid III dummy head reasonably mimics that of the comparable human (50th percentile male in the present study), the inertial effect of the dummy head should not confound $F_{z}$ readings from its upper neck load cell.

In all three tests within the present study, $F_{z}$ values for ATD axial neck load were evaluated solely from the upper neck load cells, thereby taking into consideration, as much as possible, the significant differences in axial stiffness between the ATD and cadaver human neck (the lower neck $F_{z}$ sensor was not evaluated). These upper neck $F_{z}$ sensor readings were interpreted relative to the head impact loads in cadaver tests under similar dynamic conditions (described below). Given that the Hybrid III ATD neck was specifically designed to be biofidelic in dynamic, sagittal plane bending (flexion and extension) loads, neck flexion loads $\left(M_{y}\right)$ were evaluated in this study from the lower neck load cell of driver and passenger ATDs. Lateral bending loads $\left(M_{x}\right)$ were recorded and reported, but not interpreted in this study due to the lack of available biomechanical tolerance data for the human spine when subjected to lateral bending. Additional research in this important area, for both rollover and side impact crashes, is needed. 


\section{Injury Tolerance of the Human Cervical Spine}

Semantic confusion exists in the published literature regarding cervical spine tolerance or "failure load." Some investigators have reported cervical spine "failure loads" resulting from impacts to cadaver heads as the output force measured at the lower cervical spine, thereby neglecting the kinetic energy dissipation associated with vertebral fracture and/or subluxation above the position of the sensor as well as the viscoelastic response of the intervertebral discs. ${ }^{19,20}$ Other studies have reported both the input and output loads in cadaver tests of the cervical spine. ${ }^{23-26}$ These data provide a quantitative comparison of the significant differences between the input loads measured at the cadaver head versus what might be more appropriately referred to as the residual force magnitude that is recorded at the base of the cervical spine segment. No experimental cadaver work has measured and/or estimated the input loads at the superior aspect of the human neck, which is the site of the upper neck load cell in the Hybrid III dummy, when the head is subjected to an axial impact on the crown of the head. Additional research in this area is needed.

The confusion of terms regarding cervical spine failure loads in the published literature has a significant bearing on the proper interpretation of Hybrid III ATD axial neck load sensor output in controlled rollover tests such as the present study. Bahling et al. utilized $2000 \mathrm{~N}$ as a neck sensor $F_{z}$ threshold for "potentially injurious impacts (PII)" in rollovers, which is in the range of the published residual force magnitude recorded at the lower cervical spine following an injurious impact to the cadaver head. ${ }^{1,19}$ In contrast, other investigators reported the actuator (input) force at the head that was required for cervical spine injury in axial compression. ${ }^{24}$ In interpreting the ATD neck sensor data in this study, an $F_{z}$ value of $7000 \mathrm{~N}$ was utilized as a threshold of "probable (spinal) column injury," which is in the range of the published head impact loads in cadaver studies. A value of $150 \mathrm{~N}$ m was used as the threshold for probable column injury for interpretation of $M_{y}$ readings from the lower neck sensor. In reality, the true axial compressive failure load of the human cervical spine is likely slightly lower than that measured by the head input loads in cadaver tests (due to inertial effects of the cadaver head), yet substantially greater than the lower cervical spine force data reported in the same cadaver tests. Thus, the real world relevance of threshold values used for both PII and "probable column injury" as a predictor of human injury risk must be tempered, consistent with the known biofidelity limitations of the ATD neck (described previously) and the wide variation in injury tolerance of the human spine, as described below.
The biomechanical literature suggests that the tolerance of the human cervical spine to serious injury is influenced by several mechanical factors, including individual tolerance variations due to age and gender, load magnitude and loading rate, pre-alignment (initial head-to-neck position), and end conditions of the cervical spine. Pintar et al. $^{24}$ reported that serious (AIS $3+)$ cervical spine injury under axial compression loading conditions occurred at $5856 \mathrm{~N}$ with a loading rate of $3 \mathrm{~m} / \mathrm{s}$ (for a 67 -year-old female cadaver) and $11,242 \mathrm{~N}$ with a loading rate of $8 \mathrm{~m} / \mathrm{s}$ (for a 50 -yearold male cadaver). In the present study, none of the near-side, driver ATD sensors recorded upper neck $F_{z}$ values exceeding even $2000 \mathrm{~N}$ neck compression, and only one far-side passenger dummy (Test B190042) exceeded a neck sensor reading of $5856 \mathrm{~N}$ compression. Controlling for loading rate, age, and gender in a sample of 25 human cadaver head-neck compression tests, Pintar and Yoganandan ${ }^{27}$ reported that compressive tolerance varied from $7 \mathrm{kN}$ in the young (third decade) to $2 \mathrm{kN}$ in the very old (ninth decade). "Failure loads" (recorded at the lower cervical spine) ranged from $2 \mathrm{kN}$ at quasi-static loading rates to $5 \mathrm{kN}$ at dynamic loading rates $(8 \mathrm{~m} / \mathrm{s})$. Failure tolerance for the male population was $25 \%$ higher than the female population (without regard to age and rate of loading). The present study recorded roof rail-to-dummy head contacts in the range of $5 \mathrm{~m} / \mathrm{s}(11.2 \mathrm{mph})$ in the first ground strike of the SUV rollovers. ${ }^{4}$ Thus, the roof rail-to-head impact speeds in the present study were within the range of loading rates to cadaver and $\mathrm{Hy}-$ brid III ATD heads in the studies by Pintar et al. ${ }^{24,27}$

Pre-alignment of the head and neck complex when struck by (or when it strikes) the roof is a key variable in determining whether catastrophic injury will occur, and if so, the specific type of injury that will be sustained. Published biomechanical studies suggest that cervical spine pre-flexion yields a greater incidence of lower cervical compression and burst fractures than neutrally positioned spines. ${ }^{24,25}$ Restrained occupants in rollover collisions are typically pre-flexed, due to the initial locking of their belt restraint system, and thus are at higher risk of cervical spine injury in the presence of an intruding roof structure when compared to unrestrained occupants. This higher risk of roof impact for restrained vs. unrestrained occupants in rollovers was confirmed with U.S. field accident data. ${ }^{9}$ The degree of pre-flexion of the ATD necks prior to headto-roof contact in the present study was not determined because the onboard cameras were positioned behind the ATDs during the rollover tests. The seat belt load cells (i.e., excluding the two sensors described previously that malfunctioned) recorded continuous tensile loads in both lap and shoulder belts throughout 
the test interval for both driver and passenger ATDs in all three tests. This belt load data indicated that the lap-shoulder belts locked and remained locked during the first 1000 ms test interval for all ATDs in all three tests.

Nightingale et al. ${ }^{20}$ reported on the influence of boundary or end conditions of the cervical spine relative to specific injury types. When the head was unconstrained and free to translate and/or rotate away from the applied load, no cervical injury was sustained, despite high input loads to the head. In "full constraint" conditions, with the head pre-flexed along its stiffest axis (i.e., the removal of the normal cervical lordosis), buckling and burst fractures were noted. With rotational constraint (e.g., when the neck flexes forward to the point where the chin is against the sternum), bilateral locked facets typically occurred. Using cadaver spine specimens, Pintar et al. ${ }^{26}$ determined that the average peak $M_{y}$ magnitude resulting in "major" neck injury was $97 \mathrm{~N} \mathrm{~m}$ at the specific site of injury in the cervical spine (i.e., not positioned as inferior as the lower neck load cell of the Hybrid III ATDs in the present study). The peak axial head impact force ranged from 3000 to $9700 \mathrm{~N}$, with the peak flexion bending moment at the injured level ranging from 19 to $169 \mathrm{~N} \mathrm{~m}$. Thus, the degree of constraint imposed by the contacting surface, such as an intruding roof, can be a major determinant for cervical spine injury. In all three tests of the present study, the far-side, passenger ATDs recorded lower neck flexion $\left(M_{y}\right)$ loads that exceeded $175 \mathrm{~N} \mathrm{~m}$. None of the near-side, driver ATD lower neck sensors recorded peak $M_{y}$ loads exceeding $110 \mathrm{~N} \mathrm{~m}$. No dynamic test data for cervical spine tolerance in lateral bending was identified; therefore, no interpretation of the peak $M_{x}$ sensor outputs for any of the ATDs was made.

The biomechanical impact environment to which the restrained ATDs were subjected in the present study was shown to be comparable to that of published cadaver studies on the basis of the following: head impact load magnitude and direction, loading rate, pre-alignment of the ATD head and neck, and degree of rotational head constraint. Thus, a comparison of the ATD sensor outputs for upper load cell $F_{z}$ and lower load cell $M_{y}$ values to probable column injury values of $7000 \mathrm{~N}$ and $150 \mathrm{~N} \mathrm{~m}$, respectively appears scientifically reasonable, subject to the limitations described above.

\section{Roof Crush as a Correlate or Cause of Injury}

Two opposing views exist in the published literature regarding whether roof crush causes serious injury or whether it is simply associated or correlated with serious injury. One group of investigators has concluded that restrained occupants receive catastrophic head and neck injury from diving into the roof and making head-to-roof contact while the top of the vehicle/roof is striking/hitting the ground during a rollover. , $3,5,15,16$ Other investigators have concluded that serious neck injuries to restrained occupants are directly caused by the dynamic intrusion of the roof structure into the occupant's survival space during a rollover crash. ${ }^{12,13,28}$ The present study reports quantitative evidence of the temporal relationship between dynamic roof deformation, lap-shoulder seat belt loads, and restrained ATD neck loads, which provides further clarification in this scientific debate.

Objective roof/pillar deformation occurred prior to the occurrence of Peak neck loads $\left(F_{z}, M_{y}, M_{x}\right)$ for both driver and passenger ATDs in all three rollover tests. Prior to the occurrence of Peak neck loads, the driver and passenger ATD heads contacted the roof one or more times in all three tests; the magnitude of neck sensor responses ranged from 3 to $57 \%$ of the respective dummies' Peak neck loads. Thus, the restrained driver and passenger ATDs did, indeed, "dive" into the roof while the roof was in contact with the ground, resulting in Local Maximum neck load values, which in no instance exceeded $57 \%$ of the Absolute Maximum (Peak) neck load. In particular, the "diving" neck loads (Local Maxima) for the farside, passenger ATDs were only $2-13 \%$ of the Peak neck loads $\left(F_{z}\right.$ and $\left.M_{y}\right)$ for all three tests (Table 2, Fig. 4).

In each test, the Peak neck loads of the far-side, passenger ATD occurred within $10 \mathrm{~ms}$ following the time of maximum objective roof crush for all three tests, which is consistent with published inertial effects of the ATD head in transmitting an axial force to the lower neck sensors. ${ }^{24}$ In contrast, Peak neck loads for the near-side, driver ATD occurred up to $65 \mathrm{~ms}$ following the time of occurrence of objective roof crush for all three tests. The onboard cameras also revealed observable roof crush into the far-side versus the nearside occupant compartment during the time of the peak neck loads, which was completely consistent with the timing and higher neck load magnitudes of the passenger, compared to driver, ATD for all three tests.

The lap and shoulder belt load profiles for both driver and passenger ATDs provide further insights in the scientific debate regarding roof crush as a correlate versus a cause of serious injury. During the time interval of the Peak neck loads in the passenger ATDs for all three tests, the shoulder belt load, which should increase in magnitude as it resists torso augmentation, instead consistently decreased by $65-85 \%$ to only $44 \mathrm{~N}$ in some cases. The lap belt showed the same reduction in load during the time period that Peak neck load was 
recorded; it was reduced by $58 \%$ to approximately $156 \mathrm{~N}$ (Table 4, Figs. 8a and 8b). The belt load reductions occurred at the same time that on-board cameras clearly recorded the passenger ATD hanging upside down in the lap-shoulder belt and the roof crushing into the occupant space. This time of "observable" roof crush also occurred contemporaneously with the "objective" roof crush predicted by the accelerometers mounted on the SUV roof rails. The belt load that was recorded during each Peak neck load event for the far-side, passenger ATD was less than $50 \%$ of the Peak belt load in all three tests (Table 4). The shoulder and lap belt load cells indicated that the belts were off-loaded (i.e., loading decreased) as the roof crushed down on the ATD head and pushed the ATD back toward the seat cushion, away from the shoulder and lap belts, at the time of Peak neck loads (Fig. 9). Additionally, the deformation of the passenger (far-side) B-pillar lowered the upper attachment point (i.e., D-ring) for the belt, causing slack in the shoulder belt with a concomitant reduction in shoulder belt load.

\section{Repeatability and Reliability}

The FMVSS 208 dolly rollover test methodology has been criticized for its alleged lack of reliability and/ or repeatability. ${ }^{15}$ The results of this study, however, demonstrated that the 208 rollover tests are very reliable when viewed from a vehicle-based, occupant protection frame of reference. Test-to-test comparisons of the FMVSS 208 rollover results revealed remarkable similarity in predicting the time of occurrence of Peak neck loads for both driver and passenger ATDs. The Peak neck $F_{z}$ occurred in all three tests at $530 \pm 15 \mathrm{~ms}$

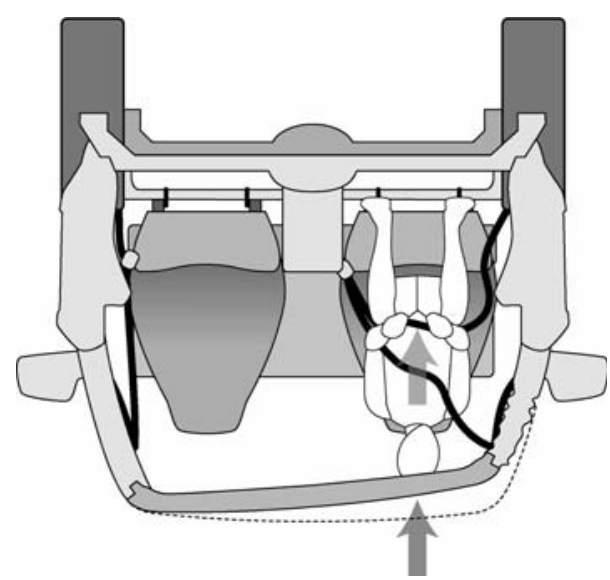

FIGURE 9. The shoulder and lap belts are off loaded (i.e., load decreases) as the roof crushes down on the passenger head and pushes the dummy back toward the seat cushion, away from the shoulder and lap belts, at the time of injurious neck loads. for the driver ATD (Fig. 10 and Table 3) and $730 \pm 15 \mathrm{~ms}$ for the passenger ATD (Table 3). The Peak neck $M_{y}$ occurred in all three tests at $530 \pm 18 \mathrm{~ms}$ for the driver ATD (Fig. 11 and Table 3) and $750 \pm 21 \mathrm{~ms}$ for the passenger ATD (Table 3). The Peak value for $M_{x}$ occurred in all three tests at $530 \pm 18 \mathrm{~ms}$ for the driver ATD and $770 \pm 13 \mathrm{~ms}$ for the passenger ATD. These small variations in time of occurrence of roof/pillar deformation and Peak neck loads are particularly remarkable given that (1) the data came from six different dummies and three different vehicles tested on three different days, (2) the differences in the time of occurrence of the Peak neck loads was $\leq 20 \mathrm{~ms}$ in an overall time interval of $1000 \mathrm{~ms}$, and (3) each $1000 \mathrm{~ms}$ time interval included either a sampling rate of 20,000 data points (B190043 and B190042) or 12,500 (B180220).

Quantitative analyses were undertaken to determine the significance probability of each pairwise comparison. Restated, the probability that the similarity of the maximum and minimum values of any two tests were related to something other than chance was analyzed (e.g., $\mathrm{B} 190042-F_{z}$ vs. $\mathrm{B} 190043-F_{z}, \mathrm{~B} 190042-F_{z}$ vs. $\mathrm{B} 190220-F_{z}$, and $\mathrm{B} 190043-F_{z}$ vs. B190220- $F_{z}$ ). Appendix 1 examines this issue and computes the probability for each pair of test metrics. This analysis revealed that there is a $93.1-98.6 \%$ probability that the differences in time occurrence of Peak neck loads between these results are NOT due to random chance alone. Stated more simply, there is a less than $7 \%$ probability that these differences are coincidental.

\section{Validity}

The constellation of driver vs. passenger neck loads measured in this test series of SUV rollovers was consistent with certain incidence trends of catastrophic head and neck injuries observed in real-world rollovers with restrained front seat occupants. ${ }^{9,21,28}$ None of the peak neck loads recorded in the near-side, driver ATD neck sensors exceeded the threshold values for probable column injury, which were used in this study. In contrast, the far-side, passenger ATDs recorded Peak neck loads that consistently exceeded the threshold for probable column injury due to neck flexion, $M_{y}$. These findings are consistent with 1992-1998 data obtained from NHTSAs National Accident Sampling System (NASS) database, which showed serious spinal injuries were more frequent for the far-side occupants (compared to the near-side), where the source was most often coded as roof, windshield, and interior. ${ }^{21}$

A probability of two common catastrophic spinal column injuries was predicted by the passenger ATD neck sensors in all three rollover tests. A combination load of compression and of flexion is associated with 


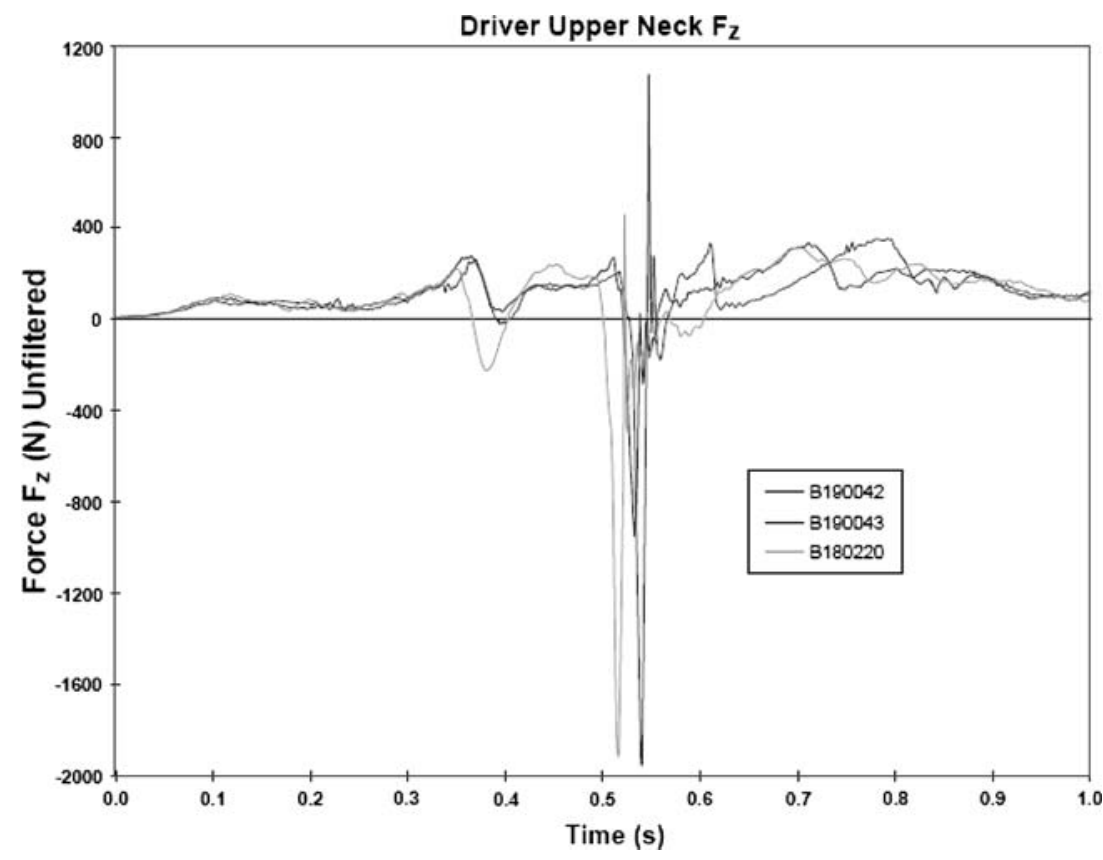

FIGURE 10. The absolute maximum value for upper neck $F_{z}$ occurred in all three tests at $530 \pm 15 \mathrm{~ms}$ for the driver dummy.

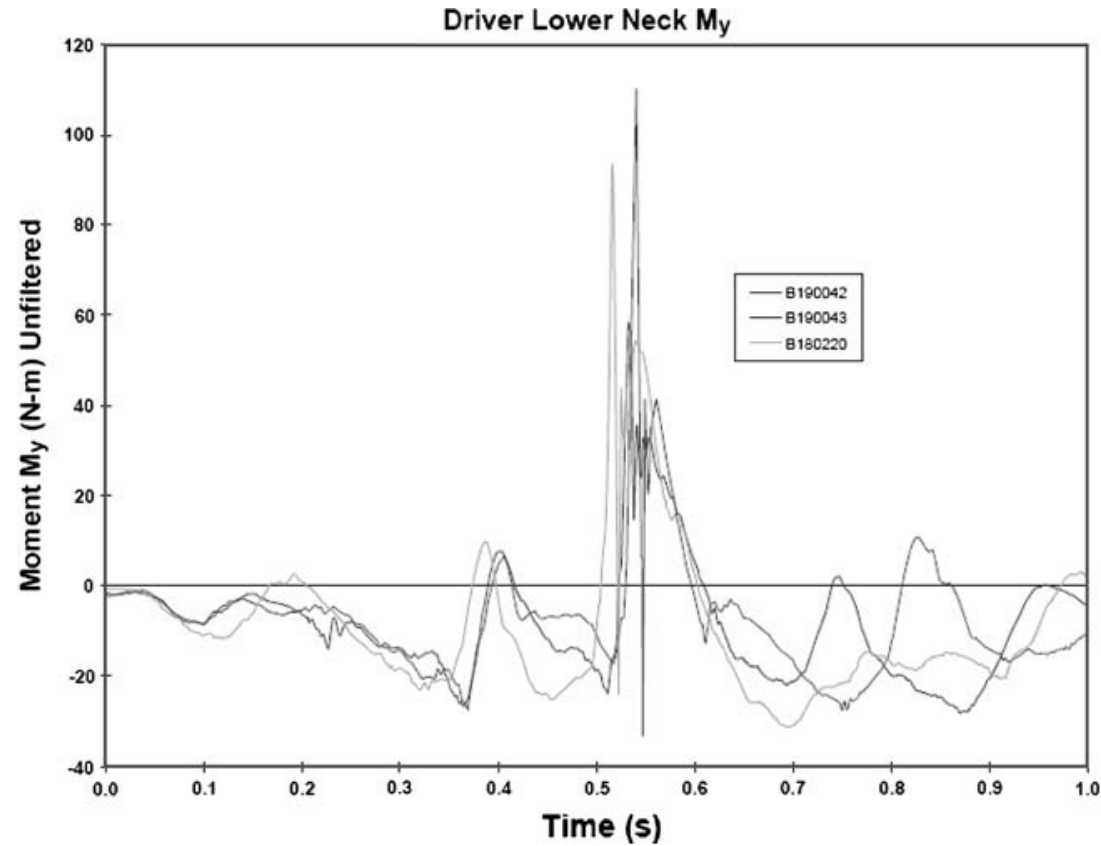

FIGURE 11. The absolute maximum value for lower neck $M_{y}$ occurred in all three tests at $530 \pm 18$ ms for the driver dummy.

burst fractures and wedge compression fractures. This load profile was recorded by the upper and lower neck sensors in the far-side passenger ATD in B190042. Bilateral facet dislocation injuries have been associated with sagittal plane flexion. ${ }^{17}$ The flexion moments recorded by the passenger ATD lower neck sensors in tests B180220 and B190043 exceeded the threshold values for probable spinal column injury by $40-240 \%$.
Thus, the results of this rollover test series suggest that the FMVSS 208 dolly rollover test may be a valid predictor of serious spinal injuries to restrained occupants in real-world rollovers.

The results of this study provide a unique data set that furthers understanding of probable spinal column injury mechanisms within a rollover crash environment. Such information may assist the scientific community and 
automotive engineers in recommending and designing appropriate intervention strategies to mitigate morbidity and mortality in rollover crashes. Moreover, these data may inform government agencies in formulating appropriate public safety policy to improve rollover crash protection for restrained occupants.

\section{CONCLUSIONS}

During each of the three FMVSS 208 dolly rollover tests of Ford Explorer SUVs, the far-side, passenger ATDs exhibited Peak neck compression and flexion loads, which indicated a probable spinal column injury in all three tests. In those same tests, the near-side, driver ATD neck loads never predicted a serious injury. In all three tests, objective roof/pillar deformation occurred prior to the occurrence of Peak neck loads $\left(F_{z}\right.$, $M_{y}$ ) for far-side, passenger ATDs, and Peak neck loads were predictive of probable spinal column injury. The production lap and shoulder seat belts in the SUVs, which restrained both driver and passenger ATDs, consistently allowed ATD head contact with the roof while the roof was contacting the ground during this 1000 ms test series. Local peak neck forces and moments were noted each time the far-side, passenger ATD head contacted ("dived into") the roof while the roof was in contact with the ground; however, the magnitude of these local maxima was only $2-13 \%$ of Peak neck loads in all three tests. "Diving-type" neck loads were not predictive of spinal column injury for either driver or passenger ATD in any of the three tests. When viewed from a vehicle-based, occupant protection frame of reference, the existing FMVSS 208 dynamic rollover test is a repeatable, reliable, and valid test method to evaluate the risk of probable spinal column injury in rollover crash environments.

\section{APPENDIX 1}

\section{Problem}

The domain of observation is a one-second time span subdivided into 20,000 time increments of $0.00005 \mathrm{~s}$. each. At each time increment, various measures of acceleration, force, and moments are recorded for a number of experiments.

Let $T_{\max }$ be the time (ms) at which the maximum value of a measure is observed in an experiment. For example, in Test B190042, the Driver-Side Peak Force was detected at $533 \mathrm{~ms}$. In Test B190043, this peak was found at $540 \mathrm{~ms}$.
So $T_{\max }(1)=533$ and $T_{\max }(2)=540$. The absolute difference between these two observations was $7 \mathrm{~ms}$. Was this a coincidence? What is the probability that the two occurrences would be that close to each other due to random chance alone?

\section{Solution}

If we assume that in any test, $T_{\max }$ is equally likely to occur at any time $t=0, \ldots, 1000 \mathrm{~ms}$, then $t$ belongs to a "uniform" probability distribution, as shown here:

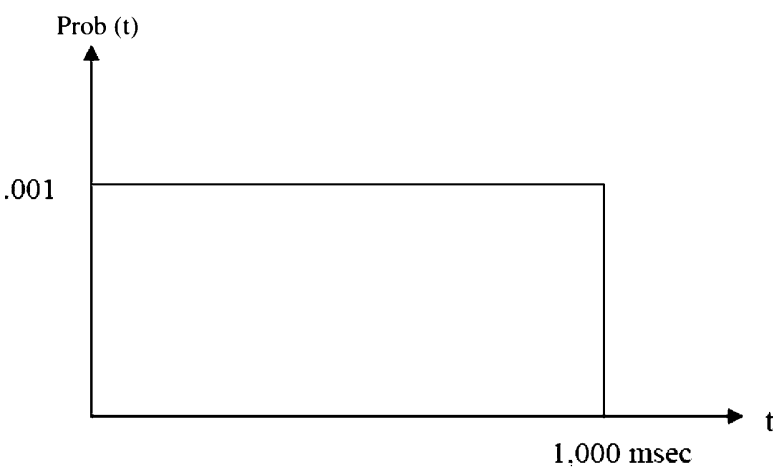

If the experiment is done twice, then $\operatorname{delta}(t)=$ $T_{\max }(1)-T_{\max }$ (2) belongs to a "triangular" distribution, as shown here:

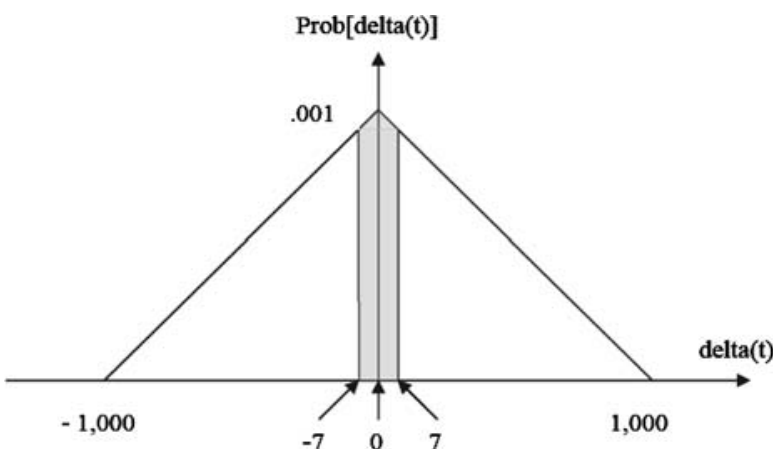

The shaded area (not drawn to scale) represents the probability that the difference between the $T_{\max }$ results in two different tests will be no more than $7 \mathrm{~ms}$.

By integration, that probability is 0.014 . In other words, there is a $98.6 \%$ probability that the difference between these results is NOT due to random chance alone. In the vast majority of statistical studies, this would be interpreted as an observation that was very unlikely to be due to chance alone.

The remainder of this study applies this reasoning to a number of measures from three experimental tests. 
Time of occurrence of roof/pillar deformation and Peak neck loads (ms).

\begin{tabular}{lccccccc}
\hline & \multicolumn{3}{c}{ Driver } & & \multicolumn{3}{c}{ Passenger } \\
\cline { 2 - 3 } \cline { 6 - 8 } $\begin{array}{l}\text { Test } \\
\text { parameter }\end{array}$ & B190042 & B190043 & B180220 & B190042 & B190043 & B180220 \\
\hline $\begin{array}{l}\text { Objective } \\
\text { roof/pillar } \\
\text { deformation }\end{array}$ & 497 & 513 & 510 & 730 & $\sim 600-800$ & 742 \\
$\begin{array}{l}\text { Peak } F_{z} \\
\text { Peak } M_{y}\end{array}$ & 533 & 540 & 516 & & 730 & 764 & 743 \\
Peak $M_{x}$ & 533 & 541 & 517 & & 729 & 764 & 751 \\
\hline
\end{tabular}

\section{Comparisons}

In making test-to-test pairwise comparisons of any result above, the general formula for the probability that the observed difference is NOT due to chance alone is given by

Significance probability $=1-0.002$ delta-t $\mid+$ $0.000001(\text { delta }-t)^{2}$

\begin{tabular}{lcccc}
\hline Test & \multicolumn{2}{c}{ Driver } \\
parameter & B190042 & B190043 & Delta- $t$ & $\begin{array}{l}\text { Significance } \\
\text { probability (\%) }\end{array}$ \\
\hline Peak $F_{z}$ & 533 & 540 & -7 & 98.6 \\
Peak $M_{y}$ & 533 & 541 & -8 & 98.4 \\
Peak $M_{x}$ & 537 & 548 & -11 & 97.8 \\
Test & \multicolumn{2}{c}{ Driver } & & Significance \\
parameter & B190042 & B180220 & Delta- $t$ & probability (\%) \\
\hline Peak $F_{z}$ & 533 & 516 & 17 & 96.6 \\
Peak $M_{y}$ & 533 & 517 & 16 & 96.8 \\
Peak $M_{x}$ & 537 & 540 & -3 & 99.4 \\
Test & \multicolumn{2}{c}{ Driver } & & Significance \\
parameter & B190043 & B180220 & Delta- $t$ & probability (\%) \\
\hline Peak $F_{z}$ & 540 & 516 & 24 & 95.3 \\
Peak $M_{y}$ & 541 & 517 & 24 & 95.3 \\
Peak $M_{x}$ & 548 & 540 & 8 & 98.4 \\
Test & \multicolumn{2}{c}{ Passenger } & & Significance \\
parameter & B190042 & B190043 & Delta- $t$ & probability (\%) \\
\hline Peak $F_{z}$ & 730 & 764 & -34 & 93.3 \\
Peak $M_{y}$ & 729 & 764 & -35 & 93.1 \\
Peak $M_{x}$ & 783 & 774 & 9 & 98.2 \\
Test & \multicolumn{2}{c}{ Passenger } & & Significance \\
parameter & B190042 & B180220 & Delta- $t$ & probability (\%) \\
\hline Peak $F_{z}$ & 730 & 743 & -13 & 97.4 \\
Peak $M_{y}$ & 729 & 751 & -22 & 95.6 \\
Peak $M_{x}$ & 783 & 760 & 23 & 95.5 \\
Test & \multicolumn{2}{c}{ Passenger } & & Significance \\
parameter & B190043 & B180220 & Delta- $t$ & probability (\%) \\
\hline Peak $F_{z}$ & 764 & 743 & 21 & 95.8 \\
Peak $M_{y}$ & 764 & 751 & 13 & 97.4 \\
Peak $M_{x}$ & 774 & 760 & 14 & 97.2 \\
\hline & \multicolumn{2}{c}{50} & \\
\hline
\end{tabular}

\section{ACKNOWLEDGMENTS}

The authors gratefully acknowledge the technical contributions of Ms. Kathryn Mergl and Ms. Sara Yeager. Financial support for this research was provided by Turner and Associates, P.C. (Little Rock, Arkansas).

\section{REFERENCES}

${ }^{1}$ Bahling, G. S., R. T. Bundorf, G. S. Kaspzyk, E. A. Moffatt, K. F. Orlowski, and J. E. Stocke. Rollover and drop tests - the influence of roof strength on injury mechanics using belted dummies. In: Proceedings of Society of Automotive Engineers (SAE) World Congress, Detroit, MI, SAE 902314, 1990.

${ }^{2}$ Bidez, M. W., J. E. Cochran, and D. King. Roof crush as a source of injury in rollover crashes - an independent analysis of Autoliv SUV rollover tests B190043, B190042, B180220, B180219, March 30, 2005, Docket No. NHTSA1999-5572-120, Available online at http://dmses.dot.gov/ docimages/pdf74/144663_web.pdf (accessed 04-30-07).

${ }^{3}$ Carter, J. W., J. L. Habberstad, and J. Croteau. A comparison of the controlled rollover impact system (CRIS) with the J2114 Rollover Dolly. In: SAE 2002 World Congress, SAE 2002-01-0694.

${ }^{4}$ Cochran, J. E., M. W. Bidez, and D. King. A method to evaluate dynamic vs. residual roof rail deformation in dolly rollover tests, ESV Paper Number 05-0378, 2005.

${ }^{5}$ Cooper, E. R., E. A. Moffatt, A. M. Curzon, B. J. Smyth, and K. F. Orlowski. Repeatable dynamic rollover test procedure with controlled roof impact. In: 2001 SAE World Congress, Detroit, MI, SAE 2001-01-0476.

${ }^{6}$ Daly, L., M. J. Kallan, K. B. Arbogast, and D. R. Durbin. Risk of injury to child passengers in sport utility vehicles. Pediatrics 117:9-14, 2006.

${ }^{7}$ DeHaven, H. Accident survival: airplanes and passenger cars. SAE 716, 1952, pp. 1-7.

${ }^{8}$ Deng, Y. C. Anthropomorphic dummy neck modeling and injury considerations. Accident Anal. Prevent. 21(1):85$100,1989$.

${ }^{9}$ Digges, K. H., A. C. Malliaris, and H. J. Deblois. Opportunities for casualty reduction in rollover crashes. In: Proceedings of the Fourteenth International Technical Conference on the Enhanced Safety of Vehicles, Munich, Germany, Paper No. 94-S5-0-11, 1994.

${ }^{10}$ Foster, J. K., J. O. Kortege, and M. J. Wolanin. Hybrid III - a biomechanically based crash test dummy. In: Proceedings of the 21st Stapp Car Crash Conference, SAE Paper No. 770938, 1977.

${ }^{11}$ Franchini, E. The crash survival space. In: 1969 SAE World Congress, Detroit, MI, SAE 690005.

${ }^{12}$ Friedman, D. F., and K. Friedman. Roof crush versus occupant injury from 1988 to 1992 NASS. In: SAE International Congress and Exposition, Detroit, MI, February 23-26, 1998, SAE 980210.

${ }^{13}$ Friedman, D. F., and C. Nash. Reducing rollover occupant injuries: how and how soon. In: 19th International Technical Conference on the Enhanced Safety of Vehicles, Washington, D.C., June 6-9, 2005, Paper 05-0417. 
${ }^{14}$ Malliaris, A. C., R. Hitchcock, and M. Hansen. Harm causation and ranking in car crashes. In: International Congress \& Expo, February 25, 1985, Detroit, MI, SAE 850090

${ }^{15}$ Moffatt, E. A., E. R. Cooper, J. J. Croteau, K. F. Orlowski, D. R. Marth, and J. W. Carter. Matched-pair rollover impacts of roll caged and production roof cars using the controlled rollover impact system (CRIS), 2003 SAE World Congress, SAE 2003-01-0172.

${ }^{16}$ Moffatt, E. A., E. R. Cooper, J. J. Croteau, C. Paranteau, and A. Toglia. Head excursion of seat belted cadaver, volunteers and Hybrid III ATD in a dynamic/static rollover fixture. In: 1997 SAE World Congress, Detroit, MI, SAE 973347, pp. 509-525.

${ }^{17}$ Myers, B. S., and B. A. Winkelstein. Epidemiology, classification, mechanism and tolerance of human cervical spine injuries. Crit. Rev. Biomed. Eng. 23(5/6):307-409, 1995.

${ }^{18}$ National Highway Traffic Safety Administration (NHTSA). National Center for Statistics and Analysis, DOT Report HS 810623: Traffic Safety Facts_-2005 Data, 2005.

${ }^{19}$ Nightingale, R. W., J. H. McElhaney, D. L. Camacho, M. Kleinberger, B. A. Winkelstein, and B. S. Myers. The dynamic responses of the cervical spine: buckling, end conditions, and tolerance in compressive impacts, 1997 SAE World Congress, Detroit, MI, SAE 973344, pp. 451-471.

${ }^{20}$ Nightingale, R. W., B. S. Myers, J. H. McElhaney, B. Doherty, and W. J. Richardson. The influence of end condition on human cervical spine injury mechanisms. In: SAE Conference Proceedings, SAE 912915, 1991, pp. 391-399.

${ }^{21}$ Paranteau, C., M. Gopal, and D. Viano. Near and far-side adult front passenger kinematics in a vehicle rollover. In: 2001 SAE World Congress, Detroit, MI, SAE 2001-010176.
${ }^{22}$ Paranteau, C., and D. Viano. Field data analysis of rear occupant injuries part II: children, toddlers, and infants. In: 2003 SAE World Congress, Detroit, MI, SAE 2003-010154 .

${ }^{23}$ Pintar, F. A., N. Yoganandan, A. Sances Jr., J. Reinartz, G. Harris, and S. J. Larson. Kinematic and anatomical analysis of the human cervical spinal column under axial loading. In: 1989 SAE World Congress, Detroit, MI, SAE 892436.

${ }^{24}$ Pintar, F. A., A. Sances Jr., N. Yoganandan, J. Reinartz, D. J. Maiman, J. K. Suh, G. Uunger, J. F. Cusick, and S. J. Larson. Biodynamics of the total human cadaveric cervical spine. In: 1990 SAE World Congress, Detroit, MI, SAE 902309, pp. 55-72.

${ }^{25}$ Pintar, F. A., N. Yoganandan, L. Voo, J. F. Cusick, D. J. Maiman, and A. Sances Jr. Dynamic characteristics of the human cervical spine. In: 1995 SAE World Congress, Detroit, MI, SAE 952722.

${ }^{26}$ Pintar, F. A., L. M. Voo, N. Yoganandan, T. H. Cho, and D. J. Maiman. Mechanisms of hyperflexion cervical spine injury. In: Proceedings of the IRCOBI Conference, Goteborg, Sweden, 1998, pp. 249-260.

${ }^{27}$ Pintar, F. A., N. Yoganandan, and L. Voo. Effect of age and loading rate on human cervical spine injury threshold. Spine 23(18):1957-1962, 1998.

${ }^{28}$ Rains, G. C., and J. N. Kanianthra. Determination of the significance of roof crush on head and neck injury to passenger vehicle occupants in rollover crashes. In: $1995 \mathrm{SAE}$ World Congress, Detroit, MI, SAE 950655.

${ }^{29}$ Yoganandan, N., A. Sances Jr., and F. A. Pintar. Biomechanical evaluation of the axial compressive responses of the human cadaveric and manikin necks. J. Biomech. Eng. 111:250-255, 1989. 